Institute of
Medicinal Plants

Research Article

\title{
Simultaneous ultrasound-assisted hydrodistillation of essential oil from aerial parts of the Satureja khuzistanica Jamzad and its antibacterial activity
}

\author{
Seyed Reza Rasouli ${ }^{1}$, Samad Nejad Ebrahimi ${ }^{1}$, Hassan Rezadoost ${ }^{1}{ }^{*}$ \\ ${ }^{1}$ Department of Phytochemistry, Medicinal Plants and Drugs Research Institute, Shahid Beheshti University, \\ Evin, Tehran, Iran
}

\begin{tabular}{|c|c|}
\hline ARTICLE INFO & ABSTRACT \\
\hline $\begin{array}{l}\text { Keywords: } \\
\text { Stureja khuzistanica } \\
\text { Lamiaceae } \\
\text { Carvacrol } \\
\text { Ultrasound-assisted } \\
\text { hydrodistillation } \\
\text { Distillate } \\
\text { Antibacterial }\end{array}$ & $\begin{array}{l}\text { Background: Ultrasonic assisted extraction (UAE) is a robust and efficient method as a } \\
\text { desirable alternative to conventional strategies for extracting active ingredients from } \\
\text { different parts of plants. Coupling this technique with hydrodistillation is an effective } \\
\text { method for producing essential oil from plant material. Objective: In this study, we } \\
\text { successfully combined ultrasonic technology with hydrodistillation (HD) and optimized } \\
\text { the system to reduce the time of the isolation and increase the yield of the essential oil } \\
\text { obtained from Stureja khuzistanica Jamzad (SK). Methods: In the next step, isolation } \\
\text { time, yield, and quality of essential oils obtained by conventional and ultrasonic-assisted } \\
\text { methods were compared. Ethyl acetate (EA) was used to recover the remaining essential } \\
\text { oil in the distillate. Results: All oils and distillates were analyzed qualitatively and } \\
\text { quantitatively via the GC-FID and GC-MS techniques. The minimum inhibitory } \\
\text { concentration (MIC) of SK essential oil against Escherichia coli (0.5 mg/ml to } 8.0 \\
\text { mg/ml) and Staphylococcus aureus (0.25 mg/ml to } 8.0 \mathrm{mg} / \mathrm{ml}) \text { were calculated. } \\
\text { Conclusion: Our results show that while the obtained essential oils chemical profile and } \\
\text { biological properties are comparable, this method can enhance essential oil isolation } \\
\text { yield efficiency by up to } 40 \% \text {. }\end{array}$ \\
\hline
\end{tabular}

\section{Introduction}

As a result of industrialization during the past and the present century, the mass production and consumption of unhealthy food products, especially in developing countries, is increased [1]. One of the best alternatives for many harmful chemicals, food additives, and pharmaceutical products is natural essential oils [2]. Many essential oils were recently identified as green alternatives as a natural antioxidant and natural antimicrobial for replacing hazardous chemical and synthetic products in the food, cosmetic and pharmaceutical industries [3]. With the growth of these industries, the demand for natural essential oils has dramatically increased. Many procedures have been used to isolate the essential oils from the desired plants, all of which are based on distillation and extraction techniques [4]. Water

Abbreviations: UAE, Ultrasonic Assisted Extraction; HD, Hydrodistillation; SK, Satureja khuzistanica Jamzad; EA, Ethyl Acetate; MIC, Minimum Inhibitory Concentration

*Corresponding author: $\underline{h \_r e z a d o o s t @ s b u . a c . i r}$

doi: $10.52547 /$ jmp. 20.80 .47

Received 18 September 2021; Received in revised form 28 November 2021; Accepted 30 November 2021

(C) 2020. Open access. This article is distributed under the terms of the Creative Commons Attribution-NonCommercial 4.0 International License (https://creativecommons.org/licenses/by-nc/4.0/) 
and steam distillation are the main techniques applied to isolate essential oils from plant materials $[5,6]$. These techniques are timeconsuming and need many infrastructures, triggering many researchers to look for more reasonable procedures to isolate desired essential oils. Microwave-assisted extraction (MAE) [7], liquid-phase microextraction (LPME) [8], membrane-based extraction techniques [9], and supercritical fluid extraction (SFE) [10] are the most utilized techniques for the isolation and extraction of essential oils from plant sources.

Recently, a novel method has been developed to isolate essential oil using a combination of hydrodistillation and ultrasonic techniques [11 13]. Ultrasound-assisted extraction (UAE) is a robust and effective method as a desirable alternative for the conventional strategies used to extract active ingredients from different parts of plants [14]. During a typical UAE procedure, an ultrasonic wave passes through the target sample tissue, causing the solvent to penetrate the sample and extract the target molecules effectively. The ultrasonic wave's primary goal is to facilitate the mass transfer between the sample and the extraction solvent [15]. Applying the ultrasound wave is usually carried out via two different strategies: ultrasonic bath and ultrasonic probes. In both systems, the piezoelectric transducers are adopted as vibration sources [16]. The only difference between these two strategies is how the ultrasonic energy is transferred, wherein in an ultrasonic bath, the power is homogenously dispersed, whereas, in a probebased system, the ultrasound energy is focused due to the use of a conical horn [17-19].

Also, different methodologies such as ultrasound pretreatment and direct Sonohydrodistillation were applied. The data revealed the maximum yield at the minimum time that could be obtained when the direct application of ultrasound (sono-clevenger) was used [20]. Pingret et al. developed a new process employing ultrasound technology to improve the hydrodistillation extraction (sono-clevenger) of fresh orange peel essential oil [11]. However, the data do not show significant differences in final yields but improve over the conventional clevenger technique. Some reports approved using ultrasound probes in continuous and pulsed pretreatments combined with the traditional hydrodistillation process resulted in shorter extraction time and higher extraction yields compared to the non-sonicated leaves [21]. The available studies on the ultrasonic pretreatment of plant materials for essential oil isolation suggest that low frequencies ranged from 20 to $50 \mathrm{~kW}$ and sonication time ranged from 20 to 40 min. Thereupon a time reduction to near $70 \%$ concerning the conventional hydrodistillation was obtained [20]. This may be accompanied by a growth in the extraction of bioactive compounds and consequently improving the biological activities of essential oils [20, 21]. Furthermore, ultrasound-assisted extraction (UAE) combined with other extraction technologies such as supercritical extraction allowed reduced time and solvent volume [20, 22-27].

The genus Satureja, commonly known as savory, is an aromatic plant endemic to the Middle-East, South-Eastern Europe, North Africa, and Central Asia and belongs to the Lamiaceae family [28]. These plants were widely prescribed in traditional medicine as a remedy for different types of diseases. The plants of this genus have been used for curing crucial diseases such as muscular pains [29], stomach, bowel disorders [30], nausea [31], indigestion [32], and diarrhea [33, 34]. In Iran, seventeen Satureja species grow indigenously, and some cultivate food and pharmaceutical applications. S. khuzistanica Jamzad (SK) is an endemic 
species to Iran [35]. SK, was used as a flavoring agent in the food industry due to its aromatic and antiseptic properties[36]. Moreover, SK essential oil was shown antibacterial activities because of the high level of carvacrol in the essential oil in a study conducted by Deans et al. [37]. Therefore the efficient isolation of high purity SK essential oil is valuable.

A new method was used for ultrasonic-assisted hydrodistillation with in-line distillate extraction to isolate SK essential oil efficiently. Both methods were successfully coupled via an innovative approach. This was followed by an online liquid-liquid extraction strategy for the chemical profiling of corresponding distillates. The isolated essential oils were qualitatively and quantitatively analyzed by gas chromatography equipped with a mass spectrometry detector. Two main components of essential oil were successfully identified and determined using the proposed procedure as an applicable method to isolate the essential oils from plant samples. Hence, their antibacterial activities were tested against gram-positive and gram-negative bacteria.

\section{Materials and Methods}

\subsection{Materials and apparatus}

GC-grade ethyl acetate (EA) was purchased from Sigma-Aldrich (Milwaukee, WI, USA). The ultrapure water used in the experiments was obtained from an AquaMax ultra-pure water purification system from Younglin (Seoul, South Korea). All the glass tools in this method, comprising distillation and condenser systems, were made manually in the laboratory.

\subsection{Plant material}

The aerial part $S$. khuzistanica was provided by Vasha Darou Pars Herbal Pharmaceutical Co., Qom, Iran, in 2017. The plant materials were identified by Dr. Javad Hadian and a voucher specimen (MPH-1414) at the herbarium of Medicinal Plants and Drugs Research Institute, Shahid Beheshti University, Tehran, Iran.

\subsection{Essential oil isolation}

The essential oil of each air-dried plant part $(50 \mathrm{~g})$ was isolated by hydrodistillation threetime using a clevenger-type apparatus recommended by the British Pharmacopoeia. The essential oil content of plant materials was determined by repeating experiments three times. The essential oils were dried over anhydrous sodium sulfate and kept at $4{ }^{\circ} \mathrm{C}$ in dark vials until analyzed and tested.

\subsection{UAE followed by hydrodistillation}

The hyphenation of ultrasonic-assisted ultrasonic homogenizer (UP200S; Hielscher, Teltow, Germany) equipped with a titanium probe of $14 \mathrm{~mm}$ in diameter was employed. The sono-clevenger has been hyphenated with an ultrasound device according to the schematic representation in Fig. 1. The sonication power $(20,30$, and $50 \mathrm{~W}$ at $24 \mathrm{kHz})$ was used to isolate essential oil in the sono-clevenger method with 30 seconds on/off interval. The distilled water passed through the EA $(20 \mathrm{ml})$ as an extraction solvent used as an online liquid-liquid extraction system. The flow rate of distilled water passing the solvent was $1.5 \mathrm{ml} / \mathrm{min}$. Eventually, the collected EA was evaporated under reduced pressure by a Heidolph rotary vacuum evaporator. The residual essential oil was reserved for further analysis.

\subsection{Analysis, identification, and quantification} of the oil components GC-FID and GC-MS analysis

The analysis was carried out on a fused silica capillary DB-5 column $(30 \mathrm{~m} \times 0.25 \mathrm{~mm}$ i.d.; film thickness $0.25 \mu \mathrm{m})$. The injector and 
detector temperatures were kept at 250 and $300{ }^{\circ} \mathrm{C}$, respectively. Nitrogen was used as the carrier gas at a flow rate of $1.1 \mathrm{ml} /$ minute; the oven temperature program was $60-250{ }^{\circ} \mathrm{C}\left(4{ }^{\circ} \mathrm{C}\right.$ $/ \mathrm{min}$ ) and finally held isothermally for $10 \mathrm{~min}$; the split ratio was 1:50. Gas chromatography/mass spectrometry (GC-MS) analysis was conducted using ThermoquestFinnigan gas chromatograph equipped with a fused silica capillary DB-5 column $(60 \mathrm{~m} \times 0.25$ mm i.d.; film thickness $0.25 \mu \mathrm{m}$ ) coupled with a
TRACE mass spectrometer (Manchester, UK). Helium was used as a carrier gas with an ionization voltage of $70 \mathrm{eV}$. Ion source and interface temperatures were 200 and $250{ }^{\circ} \mathrm{C}$, respectively. The mass range was 35 - $456 \mathrm{amu}$. The oven temperature program was the same as above for the GC-FID. The essential oil was diluted in EA by the proportion of 1:10 and $1 \mu 1$ injected from this solution for analysis. For GCMS analysis, the solvent delay mode has been applied.

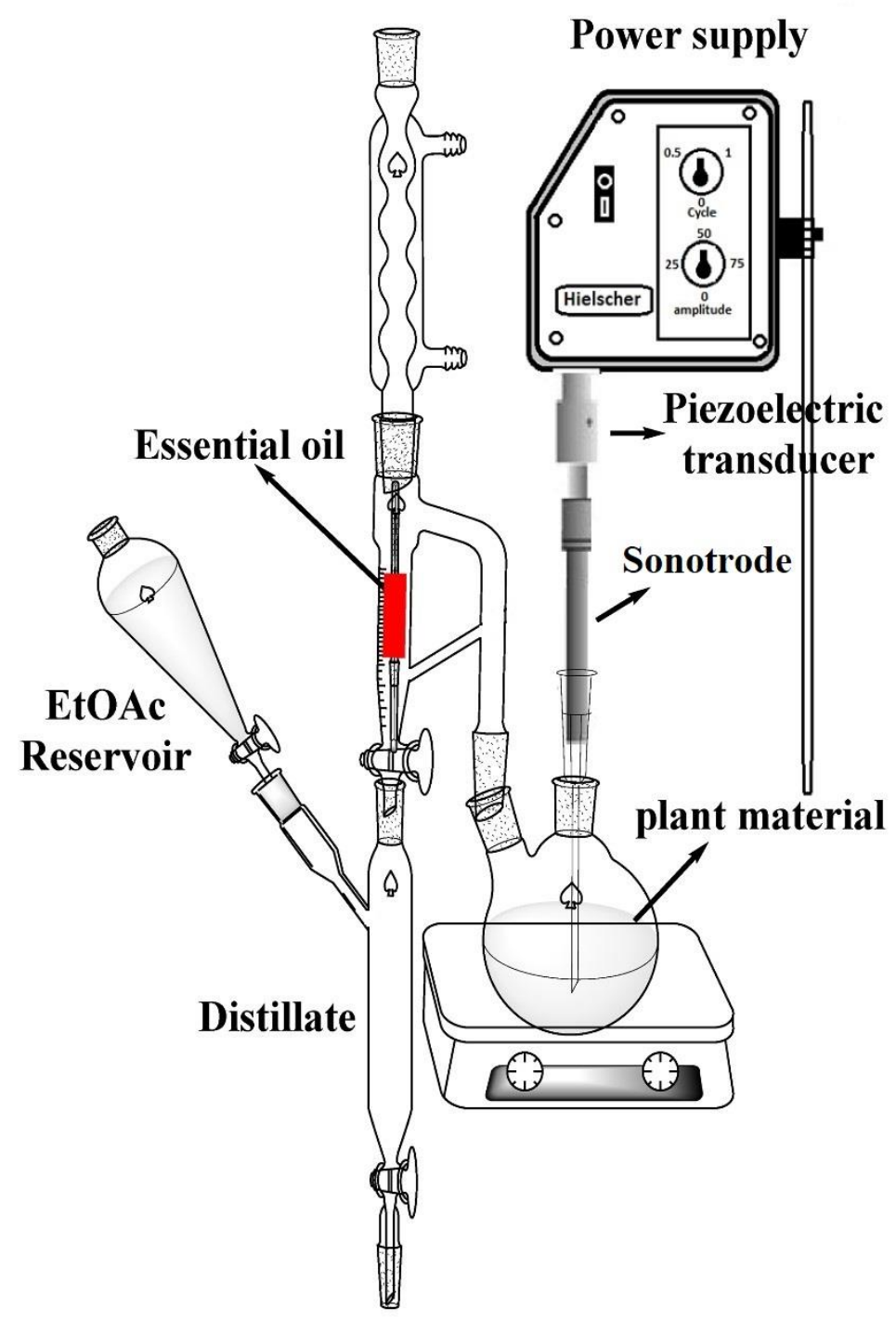

Fig. 1. Instrumental design for simultaneous ultrasonic-assisted isolation of S. khuzistanica essential oil and its corresponding distillate. 
The constituents of essential oils were identified by calculating their retention indices under temperature-programmed conditions for nalkanes $\left(\mathrm{C}_{6}-\mathrm{C}_{24}\right)$ and the oil on a DB-5 column under the same chromatographic conditions. Each compound was identified by comparing their mass spectra with those of the internal reference mass spectra library (Adams and Wiley 7.0) or with authentic compounds and confirmed by comparing their retention indices with authentic compounds or those reported in the literature [38]. For quantification purposes, relative area percentages obtained by FID were used without the use of correction factors.

\subsection{Scanning electron microscopy (SEM)}

SEM data of dried Satureja leaves were obtained for both samples undergone hydrodistillation (for 4 hours) and sonoclevenger (for $60 \mathrm{~min}$ ). The leaves were fixed on the specimen holder with aluminum tape and then sputtered with gold in a sputter coater. Finally, the plant cell photos were taken at the central laboratory of Shahid Beheshti University by using the SEM, model 3500, manufactured by Hitachi (Japan).

\subsection{Biological assays}

The bacteriostatic activity of the volatile constituents against the Gram-positive bacteria: Staphylococcus aureus (ATCC 25923), the Gram-negative bacteria: Escherichia coli (ATCC 25922) were determined using the dilution technique [39]. The oils were prepared at 10 $\mathrm{mg} / \mathrm{ml}$ using sterile distilled water containing $10 \%$ Tween 80 . Serial dilutions of the stock solutions in broth medium $(100 \mathrm{ml}$ of Muller Hinton broth) were prepared in a microtiter plate (96 wells). Following this, $1 \mathrm{ml}$ of the microbial suspension (in sterile distilled water) was added to each well. For each strain, the growth conditions and the sterility of the medium were checked, and the plates were incubated as described above. The minimum inhibitory concentrations (MIC) were determined as the lowest concentrations preventing visible growth. Standard antibiotics (Netilmicin and amoxicillin with clavulanic acid) were used to control the sensitivity of the bacteria tested.

\section{Results}

The essential oil of air-dried plant material of SK (20 g) was isolated by hydrodistillation for three $\mathrm{h}$ using a clevenger-type apparatus recommended by the British Pharmacopoeia. Then, the equipment is designed to isolate the plant's essential oil and remain in distillate by online extraction with an organic solvent (Fig. 1).

The sonication power was set at three different energy levels of 20,30 , and $50 \mathrm{~W}$, based on the literature data [11 - 13]. Considering essential oil quantity reached a constant value, EO isolation time was chosen at 60 minutes for all experiments. Table 1 presents the experimental details of the experiments designed. Consequently, the overall yield of conventional clevenger-type apparatus was $2.5 \mathrm{ml} / 100 \mathrm{~g} \mathrm{DW}$ for 4 hours. On the other hand, the isolation of essential oil with sono-clevenger system yield was $3.0,3.3$, and $3.5 \mathrm{ml} / 100 \mathrm{~g} \mathrm{DW}$ at 20,30 , and $50 \mathrm{~W}$, respectively, after 60 minutes.

Furthermore, comparing the kinetic of essential oil yield by hydrodistillation and sono-clevenger method was shown in Fig. 2. The kinetic of the extraction process can be tracked by determining the amount of essential oil yield as a function of time (or solvent consumption), providing an overall extraction curve. In brief, isolation yield maximum with the sono-clevenger technique started at a much earlier time than that with HD (25 min vs. 90 min, respectively). In the 
hydrodistillation, the isolation process of essential oil is slow, and in 90 minutes, the maximum level of $2.5 \%$ will reach, wherein sono-clevenger, this process is much faster in 30 minutes, the highest level achieved. The results show that using the ultrasound reduced the time required to achieve this yield by a factor of 3. The major effects of ultrasound in a liquid medium are attributed to the cavitation phenomena, which comes from the physical processes that create, enlarge, and implode micro bubbles of gases dissolved in the liquid. The temperature and the pressure inside of these bubbles have been estimated to be up to $5000 \mathrm{~K}$ and 5000 atm. This phenomena dramatically accelerates the chemical reactivity of the medium by which the mass transfer from plant cell will increase.

Table 1. The sample codes and experiments

\begin{tabular}{clc}
\hline Sample code & \multicolumn{1}{c}{ Description } & EO (in ml) from 100 g of SK (Yield) \\
\hline Exp. 1 & Blank sample only EA & - \\
Exp. 2 & EO obtained by hydrodistillation & 2.5 \\
Exp. 3 & EO obtained with sonication power 50 W & 3.5 \\
Exp. 4 & EO obtained by sonication power 30 W & 3.3 \\
Exp. 5 & EO obtained by sonication power 20 W & 3.0 \\
Exp. 6 & EO obtained from distillate in 50W & 0.1 \\
Exp. 7 & EO obtained from distillate in 30W & 0.1 \\
Exp. 8 & EO obtained from distillate in 20W & 0.1 \\
\hline
\end{tabular}

*SK: Stureja khuzistanica Jamzad; EA: ethyl acetate; EO: essential oil

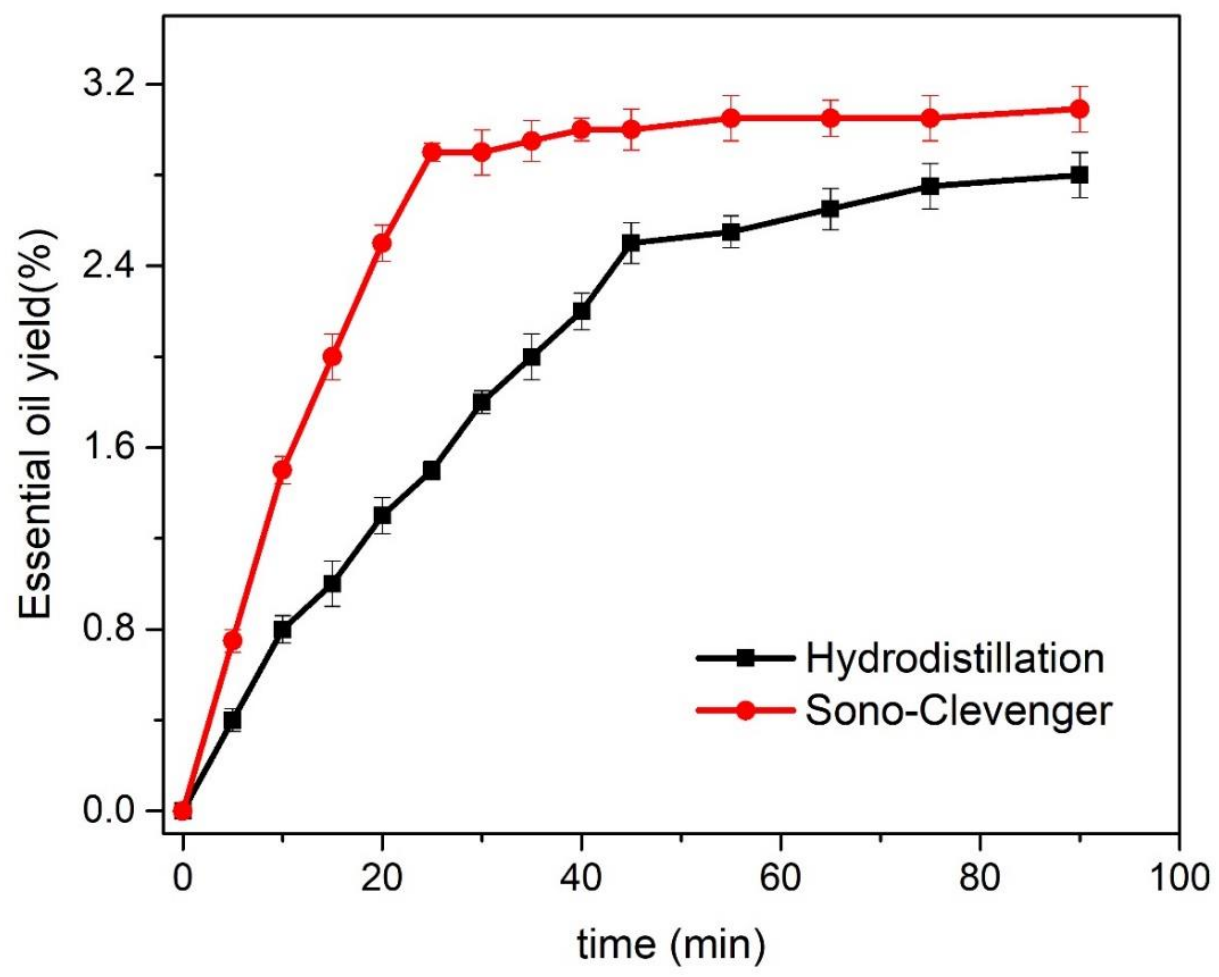

Fig. 2. The comparison of extraction yield as a function of time for hydrodistillation and the sono-clevenger method 
In another word, as shown in Fig. 3, it seems that the plant cell walls of plant secretory structures can be easily destroyed by sonic waves, thereby facilitating the release of metabolites in the extraction solvent [40]. It means sonic waves facilitate solvent to flow into the SK plant cells and enhance EO isolation from the secretory glands.

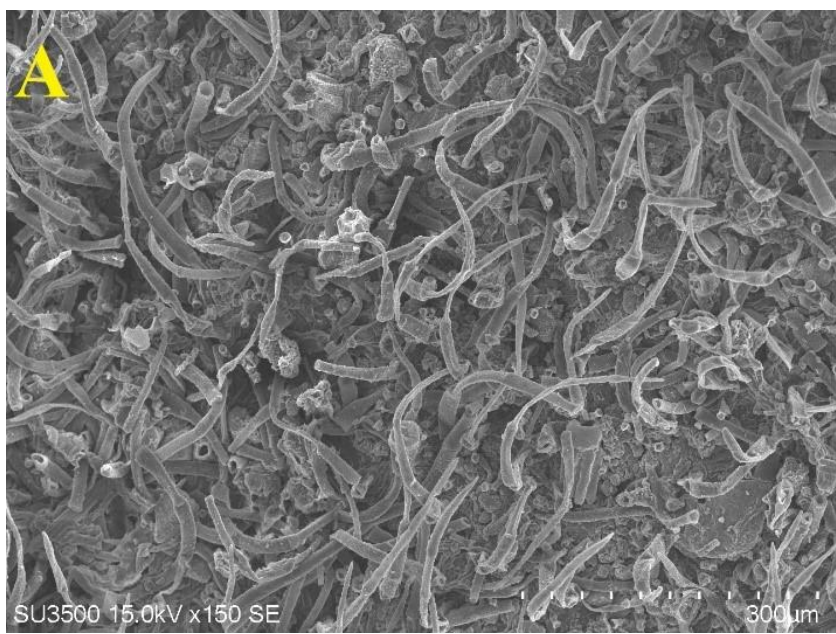

Comparing SEM data related to SK leaves treated by HD (Fig. 3A) and ultrasoundassisted HD (Fig. 3B) reveals more efficient disruption of plant cell walls by the sonic waves. As a result, an enhancement in EO extraction by about $40 \%$ compared to conventional hydrodistillation methodology was observed.

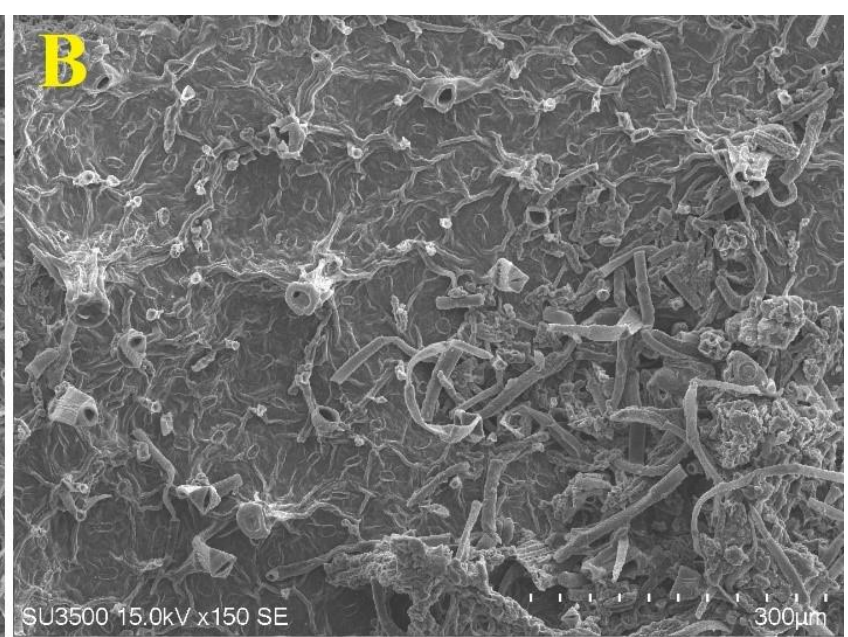

Fig. 3. Scanning electron micrographs (SEM) related to Satureja leaves: (A) after hydrodistillation for 4 hours, and (B) after sono-clevenger treatment for $60 \mathrm{~min}$.

\section{Discussion}

The GC-MS profiles for essential oils produced by conventional hydrodistillation and the sono-clevenger at three different energies were compared. The resultant hydrosols were extracted following the essential oil isolation using a liquid-liquid extraction strategy based on EA as the acceptor phase. Table 2 represents the identification of the essential oils and corresponding distillates by GC-MS and their quantification by GC-FID obtained under different conditions. Carvacrol is the most abundant phytochemical found in all studying essential oils, and distillates ranged from 96.7-98.7 \%. The other minor compounds presented in studying oils and distillates could be considered as follows: $\alpha$-pinene ranged from 0.1-0.2 \%, p-cymene (tr-1.2\%), 4-terpineol
(0.2-0.6\%) and $\gamma$-terpinene $(\operatorname{tr}-0.3 \%)$. The highest amount of carvacrol $(98.7 \%)$ was obtained at the sonication power of $50 \mathrm{~W}$. The lowest amount of carvacrol was found in the hydrodistillation. The only trace of thuja2,4(10)-diene was detected in EO obtained by conventional hydrodistillation and UAE at a power of $50 \mathrm{~W}$. The $p$-cymene quantity ranged from $0.3 \%$ to $1.1 \%$, which was at its highest amount in UAE hydrodistillation at the power of 50W. The range of $\gamma$-terpinene detected from 0.1 to $0.3 \%$ in the UAE power of $20 \mathrm{~W}$, whereas only the trace of $p$-cymene in all oils obtained by UAE, while in conventional oil and all distillates ranged from 0.1 to $0.2 \%$. A trace amount of $\alpha$-terpineol (0.03-0.2\%) was detected in all studying oils and distillates. In the conventional hydrodistillation method, 4- 
terpineol quantity was ranged from 0.2 to $0.6 \%$ in the resulting oil at a power of $30 \mathrm{~W}$. Thymol almost detected at $0.2 \%$ in all oils and distillates. The trace amount of carvacrol acetate, $\alpha$-humulene, trans-caryophyllene, and $\beta$-bisabolene are detected in studying oils and distillates. Except for some small differences, shortening the process of extracting essential oils by applying the ultrasonic technique did not result in any significant loss in the quality of EO when compared to the conventional method. There are many reports [42] in which the ultrasonic pretreatment before the hydrodistillation step has been investigated, improving both the quality and quantity of the essential oil and decreasing the time and energy consumption compared to the conventional techniques. The effects on the chemical composition were dependent on the evaluated conditions. Table 2 shows small changes such as $\alpha$-terpineol production in sono-clevenger. This may relate to the ease of releasing the essential oils from secretory glands or to transformations of unstable chemical compounds during the ultrasound application. On the other hand, an increase in the essential oil quality can be attributed to the low level of degradation of thermal compounds.

Table 2. Essential oil composition obtained from different strategies (Exp.2-Exp. 8).

\begin{tabular}{|c|c|c|c|c|c|}
\hline No & Compounds & $\mathbf{R t}$ & RI * Lit. & RI Exp. & Exp. 2 \\
\hline 1 & $\alpha$-Pinene & 3.92 & 932 & 933 & 0.1 \\
\hline 2 & Thuja-2,4(10)-diene & 5.40 & 953 & 954 & $\operatorname{tr}$ \\
\hline 3 & 1,3,6-Octatriene & 4.88 & 1032 & 1030 & $\operatorname{tr}$ \\
\hline 4 & $\gamma$-Terpinene & 5.56 & 1054 & 1053 & 0.1 \\
\hline 5 & p-Cymene & 6.27 & 1089 & 1080 & 1.1 \\
\hline 6 & $p$-Cymenene & 6.51 & 1089 & 1080 & 0.2 \\
\hline 7 & $\alpha$-Terpineol & 7.25 & 1179 & 1175 & $\operatorname{tr}$ \\
\hline 8 & Terpinen-4-ol & 9.18 & 1174 & 1180 & 0.6 \\
\hline 9 & Thymol & 10.81 & 1289 & 1270 & 0.2 \\
\hline 10 & Carvacrol & 12.81 & 1298 & 1282 & 96.8 \\
\hline 11 & Carvacrol acetate & 14.14 & 1370 & 1329 & 0.1 \\
\hline 12 & $\alpha$-Humulene & 15.22 & 1452 & 1427 & 0.1 \\
\hline 13 & trans-Caryophyllene & 17.37 & 1417 & 1425 & 0.1 \\
\hline 14 & $\beta$-Bisabolene & 13.14 & 1505 & 1501 & 0.3 \\
\hline \multicolumn{5}{|c|}{ Total identification } & 99.73 \\
\hline & \multicolumn{4}{|c|}{ Monoterpene hydrocarbons $(\mathrm{MH})$} & 1.5 \\
\hline & \multicolumn{4}{|c|}{ Oxygenated monoterpenes (MO) } & 97.7 \\
\hline & \multicolumn{4}{|c|}{ Sesquiterpene hydrocarbons (SH) } & 0.5 \\
\hline
\end{tabular}


Table 2. Essential oil composition obtained from different strategies (Exp.2-Exp. 8). (Continued)

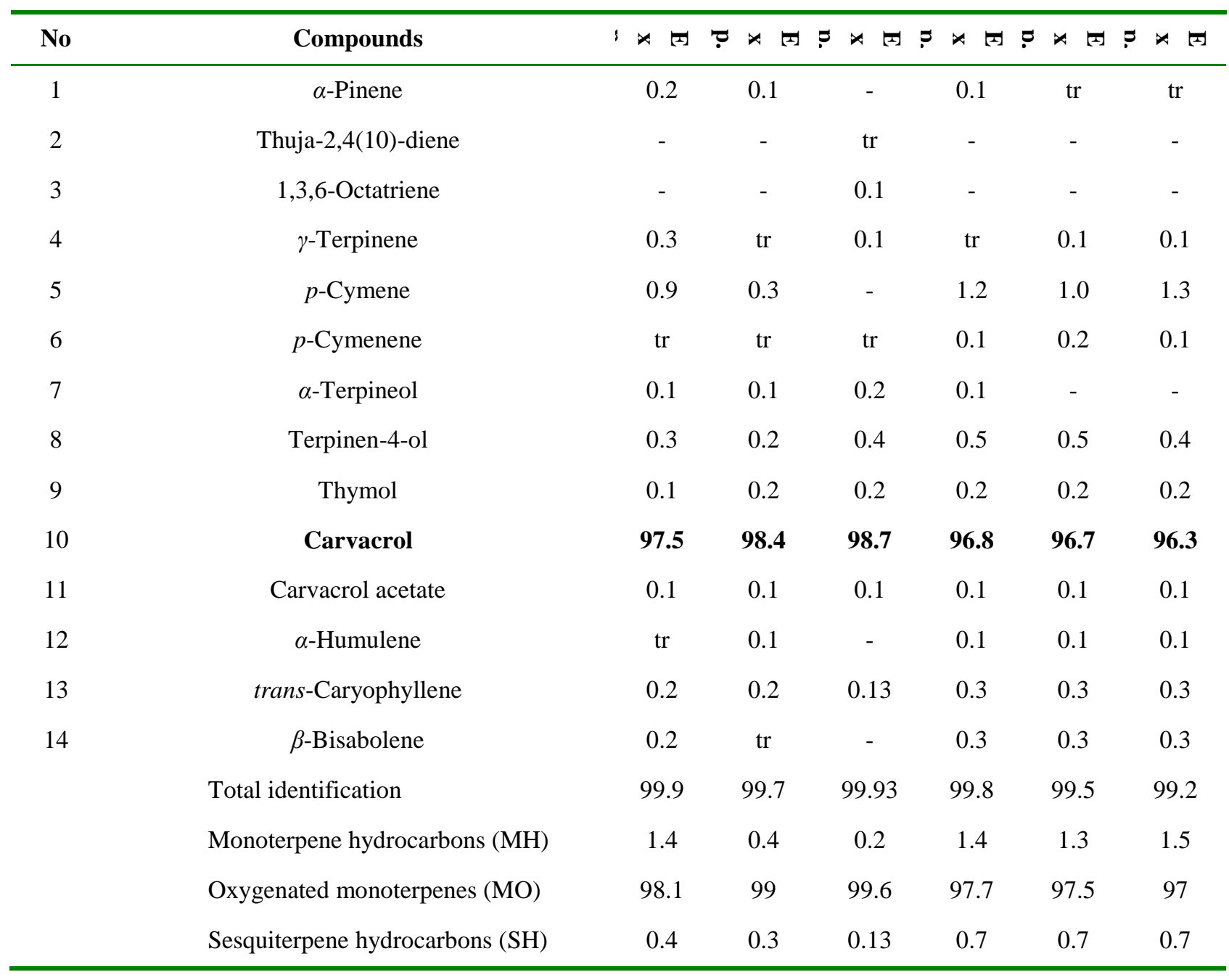

Components are listed in order of elution from a DB-5MS column. RI: Retention indices calculated against C8-C24 n-alkanes on the DB-5MS column; tr: traces <0.1, *: Retention indices based on Adams (2017); MH: Sr. No 1-6; MO: Sr. No 7-11; SH: Sr. No 12-14

The antibacterial activity (MIC) of studying oils and distillates against Escherichia coli and Staphylococcus aureus were compared. Except for the blank sample, which contains no plant materials, all EOs obtained by hydrodistillation, sono-clevenger, and distillate products showed significant antibacterial activity with MIC: 1.0 $\mathrm{mg} / \mathrm{ml} \mathrm{E}$. coli and $0.5 \mathrm{mg} / \mathrm{ml} \mathrm{S}$. aureus. The antibacterial properties of essential oil from nine Satureja species (S. bachtiarica, S. mutica, S. sahandica, S. macrantha, S. atropatana, S. edmondi, S. spicigera, S. isophylla and $S$. intermedia) were assessed [41]. On average, minimum inhibitory concentration (MIC) ranged from $4 \mathrm{mg} / \mathrm{ml}$ to $16 \mathrm{mg} / \mathrm{ml}$ against $E$. coli and 1 $\mathrm{mg} / \mathrm{ml}$ to $2 \mathrm{mg} / \mathrm{ml}$ against $S$. aureus, respectively. To conclude, our results are based on the previously reported data [42] and confirming somehow there are no significant differences among their chemistry-related biological effects.

\section{Conclusion}

In summary, the results indicate while the overall yield of conventional clevenger-type apparatus was $2.5 \mathrm{ml} / 100 \mathrm{~g}$ DW for 4 hours, using the sono-clevenger system, the overall 
yield increased up to $40 \%$ at a reduced time by a factor of 3. Furthermore, the kinetic study revealed an extraction yield with the sonoclevenger technique started at a much earlier time than that with HD (25 min vs. $90 \mathrm{~min}$, respectively). Thus, the antibacterial effect of two essential oils and their comparison of chemical profiles confirmed no significant change in the chemical composition of the essential oils. The results suggest it as an applicable method for industrial scale.

\section{Author contributions}

SRR: Experimental part, writing the manuscript, HR and SNE: Supervision,

\section{References}

1. Bicchi C, Liberto E, Matteodo M, Sgorbini B, Mondello L, Zellner BdA, Costa R and Rubiolo P. Quantitative analysis of essential oils: a complex task. Flavour. Fragr. J. 2008; 23: 38239. doi: 10.1002/ffj.1905.

2. Burt S. Essential oils: their antibacterial properties and potential applications in foods-a review. Int. J. Food. Microbiol. 2004; 94: 223253. doi: 10.1016/j.ijfoodmicro.2004.03.022.

3. Syafiq R, Sapuan S, Zuhri M, Ilyas R, Nazrin A, Sherwani $S$ and Khalina A. Antimicrobial activities of starch-based biopolymers and biocomposites incorporated with plant essential oils: A review. Polymers. 2020; 12: 2403. doi: 10.3390/polym12102403.

4. De Castro ML, Jiménez-Carmona $M$ and Fernandez-Perez V. Towards more rational techniques for the isolation of valuable essential oils from plants. TrAC. Trends. Analyt. Chem. 1999; 18: 708-716. doi: 10.1016/s01659936(99)00177-6.

5. De Castro ML and Priego-Capote F. Soxhlet extraction: Past and present panacea. $J$. experimental validation in phytochemical part, developing the draft of the paper.

\section{Conflict of interest}

The authors declare that they have no known competing financial interests or personal relationships that could have appeared to influence the work reported in this paper

\section{Acknowledgement}

The authors gratefully acknowledge the financial support of Shahid Beheshti University, Tehran, Iran. The plant material provided by Vasha Darou Pars Herbal Pharmaceutical Co and supported this research.

Chromatogr. A. 2010; 1217: 2383-2389. doi: 10.1016/j.chroma.2009.11.027.

6. Sadjia B, Naima $S$ and Chahrazed B. Extraction of thyme (Thymus pallecens de Noé) essential oil by steam-distillation, steamdiffusion and hydrodistillation processes: optimization of operating conditions and antioxidant activity. J. Essent. Oil-Bear. Plants 2012; 15: 336-347. doi: 10.1080/0972060X. 2012.10644056.

7. Lucchesi ME, Chemat F and Smadja J. Solvent-free microwave extraction of essential oil from aromatic herbs: comparison with conventional hydrodistillation. J. Chromatogr. A. 2004; 1043: 323-327. doi: 10.1016/j.chroma. 2004.05.083.

8. Deng $C$, Yao N, Wang A and Zhang $X$. Determination of essential oil in a traditional Chinese medicine, Fructus amomi by pressurized hot water extraction followed by liquid-phase microextraction and gas chromatography-mass spectrometry. Anal. Chim. Acta. 2005; 536: 237 244. doi: 10.1016/j.aca.2004.12.044. 
9. Kaufmann B and Christen P. Recent extraction techniques for natural products: microwave-assisted extraction and pressurised solvent extraction. Phytochem. Anal. 2002; 13: 105-113. doi: 10.1002/pca.631.

10. Pourmortazavi SM and Hajimirsadeghi SS. Supercritical fluid extraction in plant essential and volatile oil analysis. J. Chromatogr. A. 2007; 1163: 2-24. doi: 10.1016/j.chroma.2007.06.021. 11. Pingret D, Fabiano-Tixier A-S and Chemat F. An improved ultrasound clevenger for extraction of essential oils. Food Anal. Methods 2014; 7: 9-12. doi: 10.1007/s12161-013-9581-0. 12. Kowalski R, Gagoś M, Kowalska G, Pankiewicz U, Sujka M, Mazurek A and Nawrocka A. Effects of ultrasound technique on the composition of different essential oils. $J$. Anal. Methods. Chem. 2019; 2019. doi: 10.1155/ 2019/6782495.

13. Boubechiche Z, Chihib N-E, Jama $C$ and Hellal A. Comparison of volatile compounds profile and antioxydant activity of Allium sativum essential oils extracted using hydrodistillation, ultrasound-assisted and sonohydrodistillation processes. Indian. J. Pharm. Educ. Res. 2017; 51: S281-S285. doi: 10.5530/ijper.51.3s.30.

14. Chemat F, Rombaut N, Sicaire A-G, Meullemiestre A, Fabiano-Tixier A-S and AbertVian M. Ultrasound assisted extraction of food and natural products. Mechanisms, techniques, combinations, protocols and applications. A review. Ultrason. Sonochem. 2017; 34: 540-560. doi: 10.1016/j.ultsonch.2016.06.035.

15. Esclapez M, García-Pérez JV, Mulet A and Cárcel J. Ultrasound-assisted extraction of natural products. Food. Eng. Rev. 2011; 3: 108. doi: 10.1007/s12393-011-9036-6.

16. Santos $\mathrm{H}$ and Capelo J. Trends in ultrasonicbased equipment for analytical sample treatment.
Talanta. 2007; 73: 795-802. doi: 10.1016/ j.talanta.2007.05.039.

17. Oakley CG, Ranalletta JV, Douglas SJ and Law WK. Ultrasonic probe having articulated structure and rotatable transducer head. Google Patents. 1995, US5413107A.

18. Moholkar VS, Sable SP and Pandit AB. Mapping the cavitation intensity in an ultrasonic bath using the acoustic emission. AIChE. J. 2000; 46: 684-694. doi: 10.1002/aic.690460404.

19. Morsy NF. A short extraction time of high quality hydrodistilled cardamom (Elettaria cardamomum L. Maton) essential oil using ultrasound as a pretreatment. Ind. Crop. Prod. 2015; 65: 287-292. doi: 10.1016/j.indcrop.2014. 12.012 .

20. Nora FMD and Borges CD. Ultrasound pretreatment as an alternative to improve essential oils extraction. Cienc. Rural. 2017; 47. doi: 10.1590/0103-8478cr20170173.

21. Perera CO and Alzahrani MAJ. Ultrasound as a pretreatment for extraction of bioactive compounds and food safety: A review. LWT. 2021; 142: 111114. doi: 10.1016/ j.lwt.2021. 111114.

22. Smigielski KB, Majewska $M$ and KunickaStyczyñska A and Gruska R. The effect of ultrasound-assisted maceration on the bioactivity, chemical composition and yield of essential oil from waste carrot seeds (Daucus carota). J. Essent. Oil-Bear. Plants 2014; 17 : 1075-1086. doi: 10.1080/0972060X. 2014. 931253.

23. Hashemi SMB, Khaneghah AM, Koubaa M, Barba FJ, Abedi E, Niakousari M and Tavakoli J. Extraction of essential oil from Aloysia citriodora Palau leaves using continuous and pulsed ultrasound: Kinetics, antioxidant activity and antimicrobial properties. Process. Biochem. 2018; 65: 197-204. doi: 10.1016/ j.procbio.2017. 10.020 . 
24. Wu $Y$, Jiang $X$, Zhang $L$ and Zhou $Y$. Ultrasonic-Assisted Extraction, Comparative Chemical Composition and Biological Activities of Essential Oils of Fresh and Dry Aboveground Parts of Artemisia annua L. J. Essent. Oil-Bear. Plants. 2018; 21: 1624-1635. doi: 10.1080/ 0972060X.2019.1574244.

25. Liu X-Y, Ou H, Xiang Z-B and Gregersen H. Optimization, chemical constituents and bioactivity of essential oil from Iberis amara seeds extracted by ultrasound-assisted hydrodistillation compared to conventional techniques. J. Appl. Res. Med. Aromat. Plants 2019; 13: 100204. doi: 10.1016/ j.jarmap.2019. 100204.

26. Santos KA, Klein EJ, da Silva C, da Silva EA and Cardozo-Filho L. Extraction of vetiver (Chrysopogon zizanioides) root oil by supercritical $\mathrm{CO} 2$, pressurized-liquid, and ultrasound-assisted methods and modeling of supercritical extraction kinetics. J. Supercrit. Fluids 2019; 150: 30-39. doi: 10.1016/ j.supflu.2019.04.005.

27. Yang Y-C, Wei M-C and Hong S-J. Ultrasound-assisted extraction and quantitation of oils from Syzygium aromaticum flower bud (clove) with supercritical carbon dioxide. $J$. Chromatogr. A. 2014; 1323: 18-27. doi: 10.1016/ j.chroma.2013.10.098.

28. Ćavar S, Maksimović $M$, Šolić $M E$, Jerković-Mujkić A and Bešta R. Chemical composition and antioxidant and antimicrobial activity of two Satureja essential oils. Food. Chem. 2008; 111: 648-653. doi: 10.1016/ j.foodchem.2008.04.033.

29. Cavero RY and Calvo MI. Medicinal plants used for musculoskeletal disorders in Navarra and their pharmacological validation. $J$. Ethnopharmacol. 2015; 168: 255-259. doi: 10.1016/j.jep.2015.03.078.

Journal of Medicinal Plants
30. Dogan Y and Ugulu I. Medicinal plants used for gastrointestinal disorders in some districts of Izmir province, Turkey. Stud. Ethno-Med. 2013; 7: 149-161. doi: 10.1016/j.jep.2015.03.078.

31. Abdolhosseini S, Dabaghian FH, Mehrabani $\mathrm{M}$ and Mokaberinejad R. A review of herbal medicines for nausea and vomiting of pregnancy in traditional Persian medicine. GMJ. 2017; 6: 281-290. doi: 10.22086/gmj.v0i0.809.

32. Momtaz S and Abdollahi M. An update on pharmacology of Satureja species; from antioxidant, antimicrobial, antidiabetes and antihyperlipidemic to reproductive stimulation. Int. J. Pharmacol. 2010; 6: 343-356. doi: 10.3923/ ijp.2010.346.353.

33. Assaei R and Pajouhi N. Use of Satureja khuzestanica Essential Oil (SKEO) in the Treatment of Diarrhea: Modes of Action on Intestinal Function in Animal Model. Herb. Med. J. 2018; 3: 101-108. doi: 10.22087/herb med j.v3i3.743.

34. Baydar H, Sağdiç O, Özkan G and Karadoğan T. Antibacterial activity and composition of essential oils from Origanum, Thymbra and Satureja species with commercial importance in Turkey. Food. Control 2004; 15: 169-172. doi: 10.1016/S0956-7135(03)00028-8

35. Jamzad Z. A survey of Lamiaceae in the flora of Iran. Rostaniha. 2013; 14: 59-67. doi: 10.22092/BOTANY.2013.101317.

36. Atarés L and Chiralt A. Essential oils as additives in biodegradable films and coatings for active food packaging. Trends. Food. Sci. Technol. 2016; 48: 51-62. doi: 10.1016/j.tifs. 2015.12.001.

37. Deans $S$ and Svoboda KP. Antibacterial activity of summer savory (Satureja hortensis L) essential oil and its constituents. Int. J. Hortic. Sci. 1989; 64: 205-210. doi: 10.2298/ ABS1001159M. 
38. Sparkman OD. Identification of essential oil components by gas chromatography/quadrupole mass spectroscopy. J. Am. Soc. Mass Spectrom. 2005; 16: 1902-1903. doi.org/10.1016/j.jasms. 2005.07.008.

39. Ghorbanpour M, Hadian J, Hatami M, Salehi-Arjomand $\mathrm{H}$ and Aliahmadi A. Comparison of chemical compounds and antioxidant and antibacterial properties of various Satureja species growing wild in Iran. $J$. Med. Plant Res. 2016; 15: 58-72.

40. Gouda M, Bekhit AE-D, Tang Y, Huang Y, Huang L, He Y and Li X. Recent innovations of ultrasound green technology in herbal phytochemistry: A review. Ultrason. Sonochem. 2021; 73: 105538-105548. doi: 10.1016/ j.ultsonch.2021.105538.

41. Khaledi A and Meskini M. A systematic review of the effects of Satureja khuzestanica Jamzad and Zataria multiflora Boiss against
Pseudomonas aeruginosa. Iran. J. Med. Sci. 2020; 45: 83. doi: 10.30476/IJMS.2019.72570.

42. Nora F.M.D. and Borges C.D. Ultrasound pretreatment as an alternative to improve essential oils extraction. Cienc. 2017; 47: 1-9. doi: 10.1590/0103-8478cr20170173.

43. Seghatoleslami S, Samadi N, Salehnia A and Azimi S. Antibacterial activity of endemic Satureja khuzistanica Jamzad essential oil against oral pathogens. Iran. Endod. J. 2009; 4: 5. doi: 10.22037/iej.v4i1.1129.

How to cite this article: Rasouli SR, Nejad Ebrahimi S, Rezadoost H. Simultaneous ultrasound-assisted hydrodistillation of essential oil from aerial parts of the Satureja khuzistanica Jamzad and its antibacterial activity. Journal of Medicinal Plants 2021; 20(80): 47-59.

doi: $10.52547 / j m p .20 .80 .47$ 


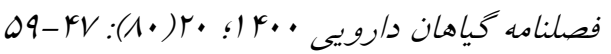

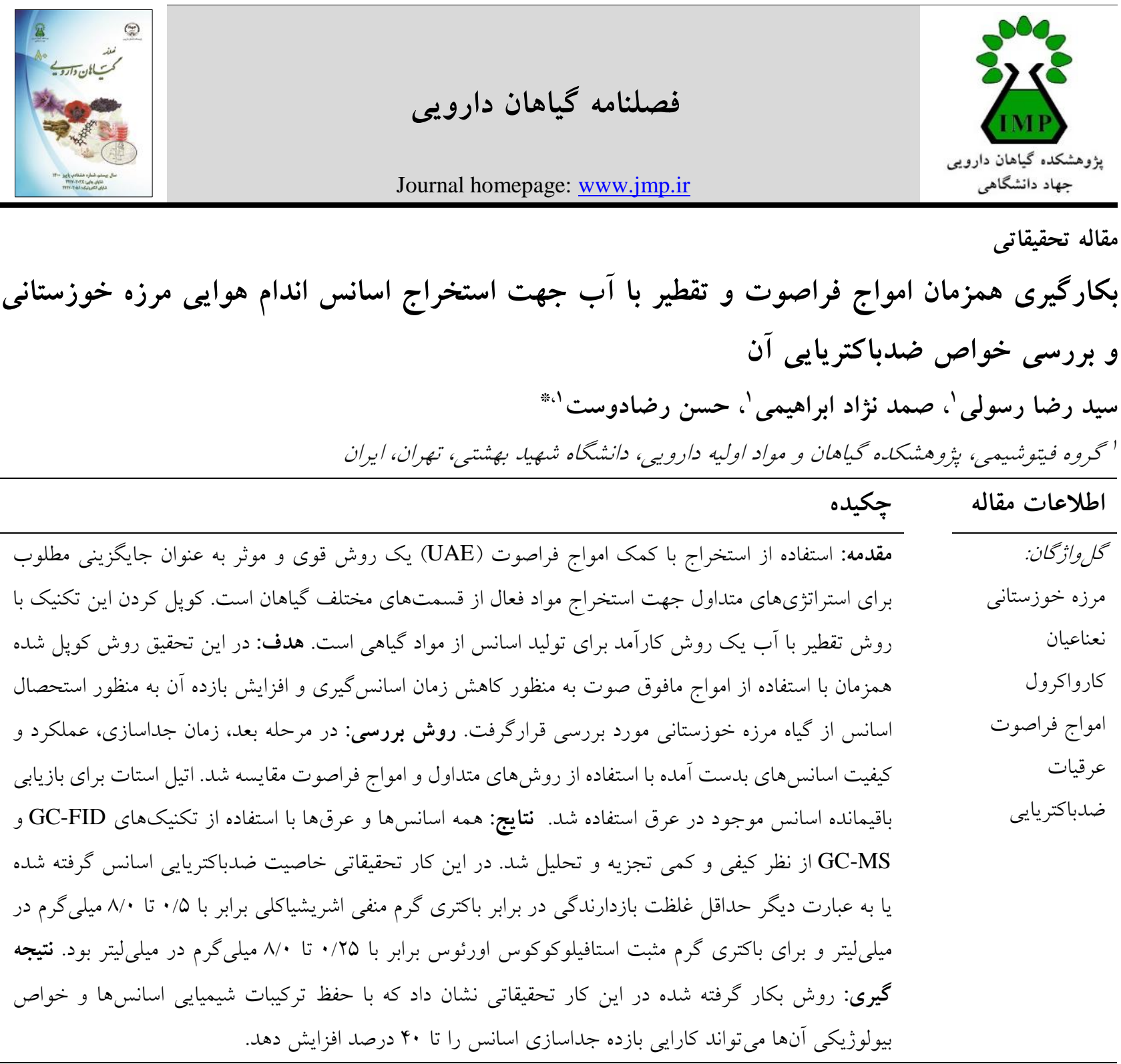

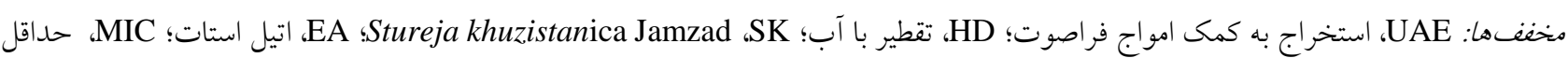
غلظت بازدارندكى

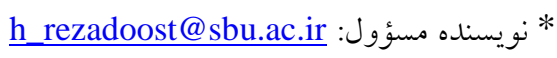
doi: $10.52547 /$ jmp. 20.80 .47

(C) 2020. Open access. This article is distributed under the terms of the Creative Commons Attribution-NonCommercial 4.0 International License (https://creativecommons.org/licenses/by-nc/4.0/) 